\title{
miR-34a inhibits esophageal squamous cell carcinoma progression via regulation of FOXM1
}

\author{
HAIBO ZHOU ${ }^{1}$, LI YANG $^{2}$, XINHUA XU ${ }^{1}$, MINGQIAN LU ${ }^{1}$, RONG GUO $^{1}$, DAOJUN LI $^{1}$, \\ QIAO HUANG ${ }^{1}$, YANG LIU ${ }^{1}$, GLENN DENG ${ }^{3,4}$ and YALIN XU ${ }^{5}$ \\ ${ }^{1}$ Institute of Oncology; ${ }^{2}$ Department of Thyroid and Breast, The First College of Clinical Medical Science, \\ Yichang Central People's Hospital Affiliated to China Three Gorges University, Yichang, Hubei 443000, P.R. China; \\ ${ }^{3}$ School of Medicine, Stanford University, Stanford, CA 94305, USA; ${ }^{4}$ Advanced Gene Diagnostics, \\ Inc. Tsinghua Science Park, Yichang, Hubei 443001; ${ }^{5}$ Department of Clinical Laboratory, \\ Chibi Pu Spinning Hospital, Chibi, Hubei 437321, P.R. China
}

Received February 14, 2018; Accepted September 26, 2018

DOI: $10.3892 / \mathrm{ol} .2018 .9593$

\begin{abstract}
Downregulation of microRNA-34a (miR-34a) has frequently been observed in esophageal squamous cell carcinoma (ESCC). However, the underlying role and molecular mechanism of miR-34a in ESCC remains largely unknown. In the current study, it was demonstrated that miR-34a was downregulated and forkhead box M1 (FOXM1), a target gene of miR-34a, was upregulated in ESCC tumor tissues. Overexpression of miR-34a decreased FOXM1 mRNA and protein expression in the ESCC cell lines tested (TE-1 and TE-8). Inhibition of miR-34a increased FOXM1 mRNA and protein levels in human esophageal epithelial cells (HEEC). In addition, miR-34a mimics reduced the relative luciferase activity of ESCC cells transfected with FOXM1 3'UTR-WT, but not FOXM1 3'UTR-Mut. The CCK8 assay and scratch wound healing assay showed that overexpression of miR-34a induced inhibition of cell proliferation and cell migration. Additionally, transfection with miR-34a mimics reduced the expression of key genes involved in cell migration (MMP2 and MMP9) in ESCC cells. Thus, the present data demonstrated that miR-34a suppressed ESCC progression by directly targeting FOXM1.
\end{abstract}

\section{Introduction}

Esophageal cancer (EC) is the 8th most frequent and the 6th most fatal cancer worldwide (1), with an occurrence of $>1: 1,000$ in high-risk northern Chinese populations, but 20-fold lower in low-risk Western African populations (2). Esophageal

Correspondence to: Dr Yalin Xu, Department of Clinical Laboratory, Chibi Pu Spinning Hospital, S1 Guihuashu Road, Lushuihu Scenic Spot, Chibi 437321, Hubei, P.R. China

E-mail: xuyalincbpsh@yeah.net

Key words: miR-34a, esophageal squamous cell carcinoma, FOXM1 squamous cell carcinoma (ESCC) or esophageal adenocarcinoma (EAC) is found in almost $95 \%$ of EC cases (1). ESCC is the main subtype of EC in China, whereas EAC is the most common subtype of EC in Western countries.

ESCC, which arises from the squamous epithelium of the esophagus, is associated with the consumption of tobacco (3). The intake of substantial amounts of alcohol, particularly in conjunction with smoking, dramatically increases the risk of squamous-cell carcinoma (although not adenocarcinoma) (4). At present, surgical resection is the main surgical treatment for EC. For patients who have curative surgery and do not progress to lymph node metastasis, the 5-year survival rate is 20-30\%; whereas, for patients with $>1$ lymph node metastasis, the 5-year survival rate is only $13 \%$ (5). Therefore, it is important to understand the molecular characteristics of EC for clinical biomarkers and therapeutic modalities.

Biomarkers have been investigated for many years, in terms of modifications in genomic DNA, specific mRNA/protein molecules or metabolites (6).

Active or mature miRNAs are 18-22 nucleotides, single-stranded RNA molecules with 50 phosphate and 30 hydroxyl groups (7). A mature miRNA can target hundreds of mRNAs and one mRNA can be targeted by various miRNAs (8). miRNAs are potential biomarkers with crucial cellular roles in healthy and diseased cells (8). The reasons for adopting miRNAs as anti-cancer drugs are the dysregulation of miRNAs in cancer and the alteration of cancer phenotypes via targeting miRNA (9). The in vivo stability of miRNAs has been successfully used in preclinical models of miRNA-based treatments (10). miR-34a acts as an important tumor suppressor in various cancers (11). CDK4/6, cyclin D1, E2F3, MYCN, SIRT1 and Bcl2, which are correlated with cell cycle and apoptosis control, are downregulated by miR-34a (11).

The present study aimed to explore the role of miR-34a in ESCC and the possible molecular mechanisms.

\section{Materials and methods}

Tissue samples. A total of 30 cases of ESCC tissues and 30 cases of adjacent non-tumor esophageal tissues were 
collected from 30 patients (17 male: 13 female) who aged at 47.21 \pm 8.33 between February, 2014 and January, 2016, from Chibi Pu Spinning Hospital. No patient had received radiotherapy or chemotherapy prior to surgery. The use of human tissues was approved by the Ethics Committee of Chibi $\mathrm{Pu}$ Spinning Hospital. Patients agreed to the use of their samples in scientific research.

Cell culture. Human esophageal epithelial cells (HEEC), Het-1A, and ESCC TE-8 and TE-1 cells were obtained from the Institute of Biochemistry and Cell Biology of the Chinese Academy of Sciences (Shanghai, China). Cell lines were cultured in RPMI-1640 medium (Hyclone; GE Healthcare, Logan, UT, USA) containing $10 \%$ heat-inactivated fetal bovine serum (FBS; Invitrogen; Thermo Fisher Scientific Inc., MA, USA), 100 U/mL penicillin (Sigma-Aldrich; Merck KGaA, Darmstadt, Germany), and $100 \mathrm{mg} / \mathrm{mL}$ streptomycin (Sigma-Aldrich; Merck KGaA) in an incubator at $37^{\circ} \mathrm{C}$ and $5 \% \mathrm{CO}_{2}$.

Cell transfections. The miRNA-34a mimics and miRNA-negative control (NC) mimics were obtained from Qiagen GmbH (Hilden, Germany). HEEC, TE-8 and TE-1 cells were transfected with miR-34a mimics or miRNA-NC mimics using Lipofectamine ${ }^{\circledR} 2000$ (Invitrogen; Thermo Fisher Scientific, Inc.), incubated at $37^{\circ} \mathrm{C}$ for $48 \mathrm{~h}$ and prepared for the following experiments. The target sequences of miRNA-34a mimics were as follows: 5'-UGGCAGUGUCUU AGCUGGUUGU-3'.

The miRNA-34a inhibitor and miRNA-NC inhibitor were purchased from Applied Biological Materials (ABM, Vancouver, Canada). HEEC cells were transfected with miR-34a inhibitor or miRNA-NC inhibitor by Lipofectamine ${ }^{\circledR}$ 2000 (Invitrogen; Thermo Fisher Scientific Inc.), incubated at $37^{\circ} \mathrm{C}$ for $48 \mathrm{~h}$ and prepared for the following experiments.

RNA isolation and quantitative real-time PCR. Total RNA from 30 samples of ESCC and non-tumor tissues, and ESCC cell lines transfected with miR-34a mimics and miRNA-NC mimics was isolated by TRIzol (Thermo Fisher Scientific, Inc.). miRNA was isolated from 30 samples of ESCC and non-tumor tissues, and ESCC cell lines transfected with miR-34a mimics and miRNA-NC mimics, using a miRNA Extraction kit (Qiagen $\mathrm{GmbH}$ ). RNA integrity was assessed using a Nano Drop ND-1000 spectrophotometer. Reverse transcription was conducted using a miRNA cDNA Synthesis Kit (Qiagen $\mathrm{GmbH}$ ). qPCR amplification was conducted using SYBR green Premix Ex Taq II (Qiagen GmbH) with the Step One Plus Real-Time PCR System (Applied Biosystems; Thermo Fisher Scientific, Inc.). The experiment was performed using an ABI Prism 7500 Sequence Detection System (Applied Biosystems; Thermo Fisher Scientific, Inc.). PCR was performed in a total volume of $25.0 \mu \mathrm{l}$ : $10 \mu \mathrm{l}$ SYBR Premix Ex Taq (2X), $1 \mu \mathrm{l}$ PCR Forward Primer, $1 \mu \mathrm{l}$ PCR Reverse Primer, $0.5 \mu \mathrm{l}$ ROX Reference Dye II $(50 \mathrm{X})^{*} 3,2 \mu \mathrm{l}$ cDNA and $8 \mu 1$ double-distilled water. The PCR reaction was performed at an initial denaturation of $10 \mathrm{~min}$ at $95^{\circ} \mathrm{C}, 95^{\circ} \mathrm{C}(5 \mathrm{sec}), 63^{\circ} \mathrm{C}(30 \mathrm{sec})$, and $72^{\circ} \mathrm{C}(30 \mathrm{sec})$ for a total of 40 cycles, with a final extension step at $72^{\circ} \mathrm{C}$ for $5 \mathrm{~min}$. The expression levels of genes were calculated by $2^{-\Delta \Delta \mathrm{Cq}}$ ( $\Delta \Delta \mathrm{Cq}=\Delta \mathrm{Cq}$ ESCC- $\Delta \mathrm{Cq}$ corresponding normal tissues) (12). Primers used were: forkhead box M1 (FOXM1) forward:
5'-TCTCAGCACCACTCCCTTG-3'; FOXM1 reverse: 5'-GGA TCTTGCTGAGGCTGTC-3'; GAPDH forward: 5'-TGCACC ACCAACTGCTTAGC-3'; GAPDH reverse: 5'-GGCATGGAC TGTGGTCATGAG-3'; miR-34a forward: 5'-CCCAGAACA TAGACACGCTGGA-3'; miR-34a reverse: 5'-ATCAGCTGG GCACCTAGGACA-3'; U6 forward: 5'-CTCGCTTCGGCA GCACA-3'; and U6 reverse: 5'-CTCGCTTCGGCAGCACA-3'. The expression level of miRNA was normalized using U6 as an internal control. The expression level of mRNA was normalized using GAPDH as an internal control.

Western blot analysis. Cells were collected and lysed in RIPA lysis buffer (Beijing Solarbio Science \& Technology Co., Ltd., Beijing, China). A total of $10 \mu$ l protein extract separated on 6-15\% SDS-PAGE and transferred onto a PVDF membrane (Immobilon $0.45 \mu \mathrm{m}$; EMD Millipore, Billerica, MA, USA). The blots were immersed in the primary antibodies of MMP-2 (cat. no: ab37150; 1:1,000; Abcam, Cambridge, MA, USA), MMP-9 (cat. no: ab76003; 1:1,000; Abcam), FOXM1 (cat. no: ab180710; 1:1,000; Abcam) and GAPDH (cat. no: ab8245; 1:1,000; Abcam) which were diluted with $5 \%$ non-fat milk overnight at $4{ }^{\circ} \mathrm{C}$; then treated with a secondary antibody (cat. no: ab97080; 1:5,000; Abcam) for $2 \mathrm{~h}$ at room temperature. Finally, the bands were exposed using electrochemiluminescence. Protein expression was normalized to GAPDH.

Luciferase reporter assay. For the luciferase reporter assay, TE- 8 and TE-1 cells were co-transfected with $20 \mathrm{mM}$ miR-34a mimic or the negative control and $200 \mathrm{ng}$ of psiCHECK-2-FOXM1-3'-UTR-WT or psiCHECK-2FOXM1-MUT, and $10 \mathrm{ng}$ Renilla luciferase vector using Lipofectamine ${ }^{\circledR} 2000$ (Invitrogen; Thermo Fisher Scientific, Inc.). Following $48 \mathrm{~h}$ transfection, cells were collected and analyzed via the Dual-Luciferase Reporter Assay System (Promega Corporation, Madison, WI, USA). Luciferase activity was detected using the GloMax fluorescence reader (Promega Corporation). The pRL-CMV Renilla luciferase reporter was the control for contrast correction in transfection efficiency.

Wound healing assay. The migratory ability of TE-1 cells was evaluated by wound-healing assay. TE-1 cells in 6-well plates were scratched with a $20 \mu \mathrm{l}$ pipette tip (Eppendorf, Hamburg, Germany) and grown in RPMI-1640 medium with 1\% FBS with $5 \% \mathrm{CO}_{2}$ at $37^{\circ} \mathrm{C}$. The extent of migration was assessed by phase contrast microscopy at 0 and $30 \mathrm{~h}$, respectively. Wound healing capacity was monitored under a microscope after $30 \mathrm{~h}$.

Cell proliferation assay. To explore the effect of miR-34a on the cell viability of TE-1 cells, the cell viability was measured using a CCK8 cell counting kit (Dojindo Molecular Technologies, Inc., Kumamoto, Japan) based on the manufacture's protocol. Briefly, $1 \times 10^{4}$ TE-1 cells were seeded into 96-well plates and allowed to grow overnight in complete DMEM (Hyclone; GE Healthcare) at $37^{\circ} \mathrm{C}$. The following day, $10 \mu \mathrm{l} \mathrm{CCK8}$ solution was added into each well and incubated for $2 \mathrm{~h}$. The absorbance of TE-1 cells at $450 \mathrm{~nm}$ was measured using a microplate reader (Bio-Rad Laboratories, Inc., Hercules, CA, USA). At 24, 48 and $72 \mathrm{~h}$ after miR-34a mimics or miR-NC mimics transfection, the cell numbers were analyzed using the CCK8 kit. 

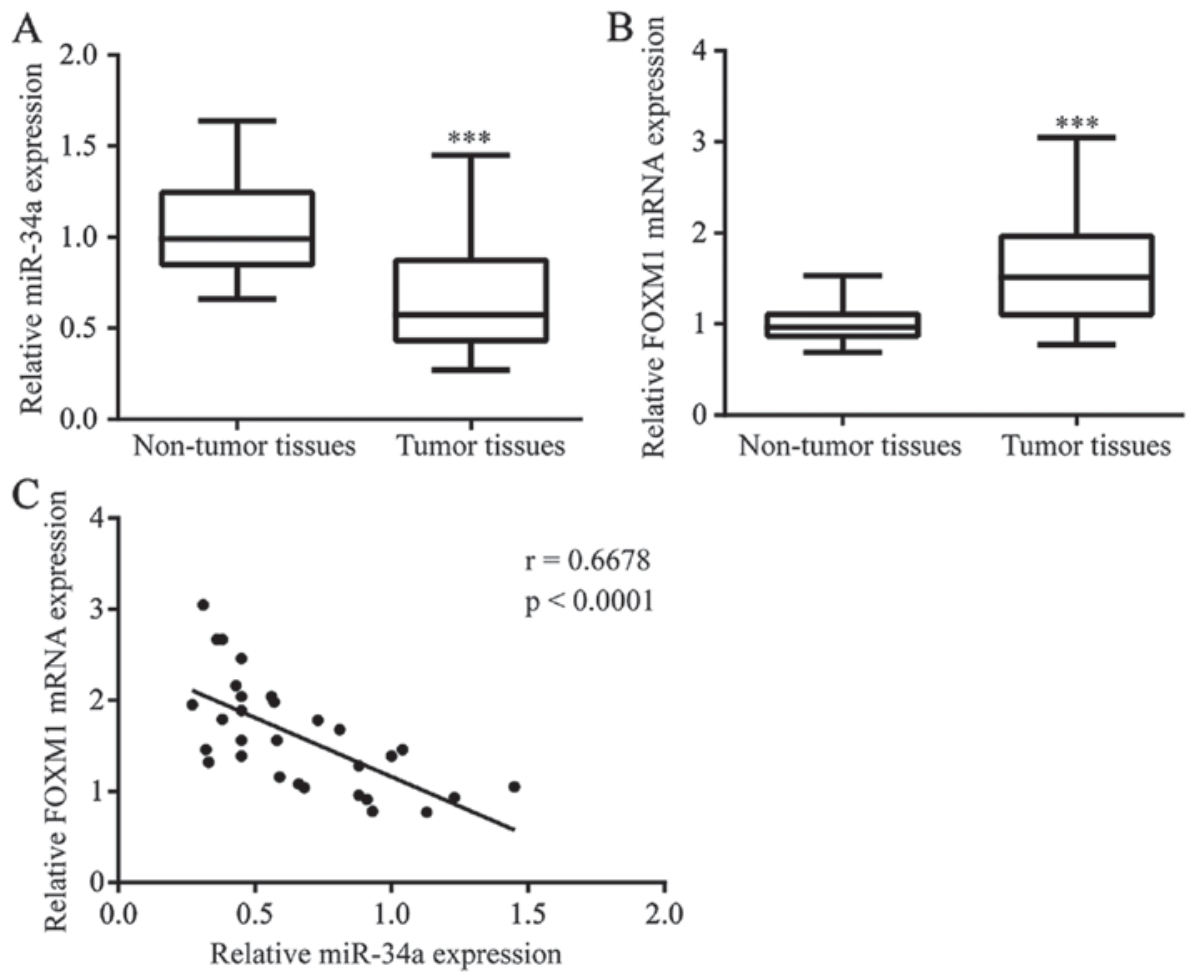

Figure 1. miR-34a level was negatively correlated with the FOXM1 mRNA level in ESCC tumor tissues. (A) A significant decrease in miR-34a was observed in tumor tissues. (B) Overexpression of FOXM1 mRNA was detected in tumor tissues compared with their non-cancerous counterparts. (C) Importantly, there was a negative association between miR-34a levels and FOXM1 mRNA levels in ESCC tumor tissues. ${ }^{* * *} \mathrm{P}<0.001$. FOXM1, forkhead box M1; ESCC, esophageal squamous cell carcinoma.

Statistical analysis. SPSS software v13.0 (SPSS, Inc., Chicago, IL, USA) was used for statistical analyses. Data are expressed as the mean $\pm \mathrm{SD}$. A paired sample t-test was used to compare FOXM1 protein expression. Spearman's correlation analysis was used to analyze the correlation between FOXM1 and miR-34a. ${ }^{*} \mathrm{P}<0.05,{ }^{* * *} \mathrm{P}<0.01$ and ${ }^{* * * *} \mathrm{P}<0.001$ were considered to indicate a statistically significant difference.

\section{Results}

Decreased expression of miR-34a in tumor tissues from ESCC. To evaluate the potential role of miR-34a in ESCC, we detected miR-34a levels in 30 tumor tissues and matched normal tissues from ESCC patients. A significant decrease in miR-34a was observed in tumor tissues (Fig. 1A). FOXM1 was reported to be a target gene of miR-34a in hepatocellular carcinoma (13). We examined FOXM1 mRNA levels in samples from ESCC patients. Overexpression of FOXM1 mRNA was detected in tumor tissues compared with their non-cancerous matched tissues (Fig. 1B). Importantly, there was a negative association between miR-34a levels and FOXM1 mRNA levels in ESCC tumor tissues (Fig. 1C).

miR-34a inhibits cell growth and cell migration in ESCC cells. To identify the function of miR-34a in ESCC, we overexpressed miR-34a in ESCC TE-1 cells by transfection of miR-34a mimics (Fig. 2A). Overexpression of miR-34a induced a decrease in the cell proliferation rate (Fig. 2B). In addition, in a wound healing assay, miR-34a overexpression reduced the wound closure areas of TE- 1 cells, indicating that the migration ability of TE-1 cells was inhibited upon miR-34a elevation (Fig. 2C and D). These data suggested that miR-34a could inhibit ESCC progression via the inhibition of cell growth and the cell migration ability of cancer cells.

miR-34a negatively regulates FOXM1 expression in ESCC cells. The negative correlation between miR-34a and FOXM1 suggested that there might be a regulatory relationship between miR-34a and FOXM1. Notably, we found that the overexpression of miR-34a reduced FOXM1 expression at both the mRNA and protein level in the cell lines tested (TE-1 and TE-8; Fig. 3A and B). In the immortal esophageal epithelium cell line HEEC, inhibition of miR-34a by transfection of the miR-34a inhibitor elevated FOXM1 expression (Fig. 3C and D).

miR-34a directlyrepresses FOXM1 expression in ESCC.FOXM1 was reported to be a target gene of miR-34a in hepatocellular carcinoma (13). The binding sites between miR-34a and FOXM1 were in consistent with that of the hepatocellular carcinoma (13). A dual luciferase reporter assay was used to further explore the regulatory relationship between miR-34a and FOXM1 in ESCC cells. In both TE-1 and TE-8 cells, overexpression of miR-34a decreased the luciferase activity of cells transfected with FOXM1 3'UTR-WT, but not 3'UTR-Mut (Fig. 4).

miR-34a suppresses FOXM1 target gene expression in ESCC cells. FOXM1 promoted cancer progression via elevating the expression of MMP-2 and MMP-9 (14). Consistently, overexpression of miR-34a downregulated MMP-2 and MMP-9, two target genes of FOXM1 involved in cell migration regulation, 


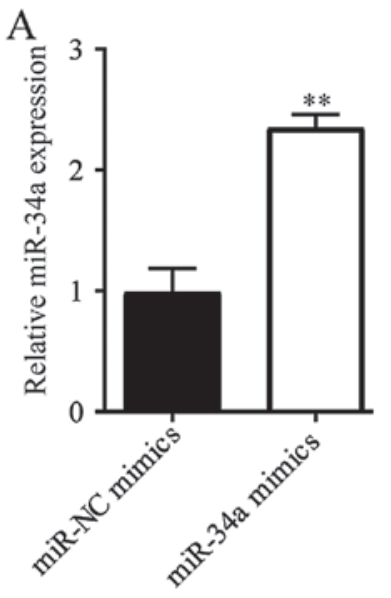

$\mathrm{C}$
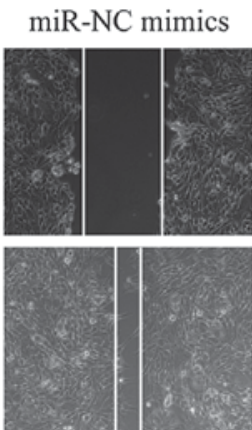

B

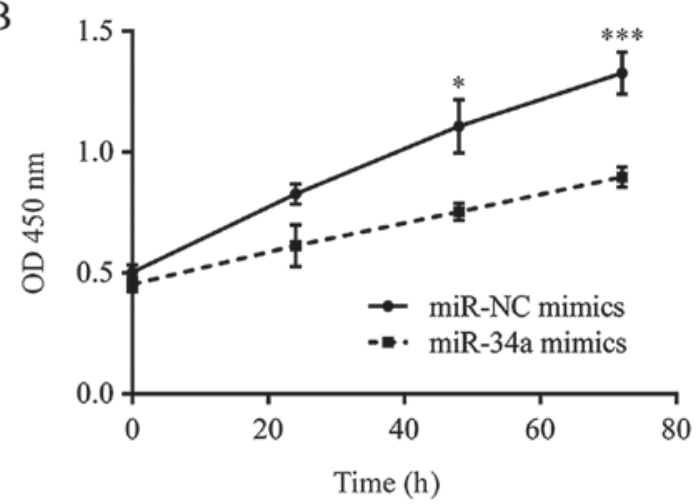

Figure 2. miR-34a inhibited cell growth and cell migration in ESCC cells. (A) We overexpressed miR-34a in ESCC TE-1 cells by transfection of miR-34a mimics. (B) Overexpression of miR-34a induced a decrease in the cell proliferation rate. (C) Representative image and (D) quantification of wound healing assay. miR-34a overexpression reduced the wound closure areas of TE-1 cells. ${ }^{*} \mathrm{P}<0.05,{ }^{* * *} \mathrm{P}<0.01,{ }^{* * * *} \mathrm{P}<0.001$. ESCC, esophageal squamous cell carcinoma.

$\mathrm{A}$.
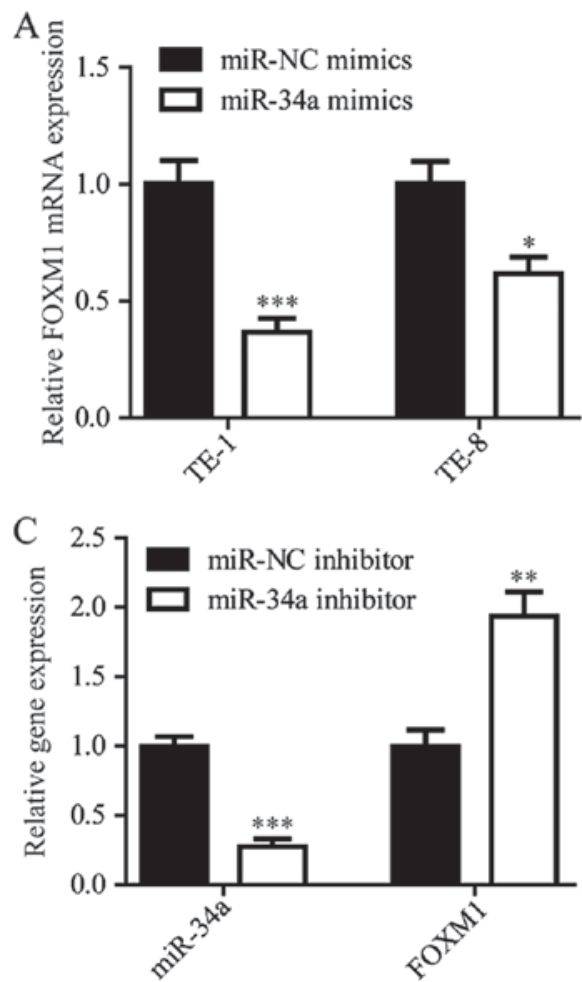

B

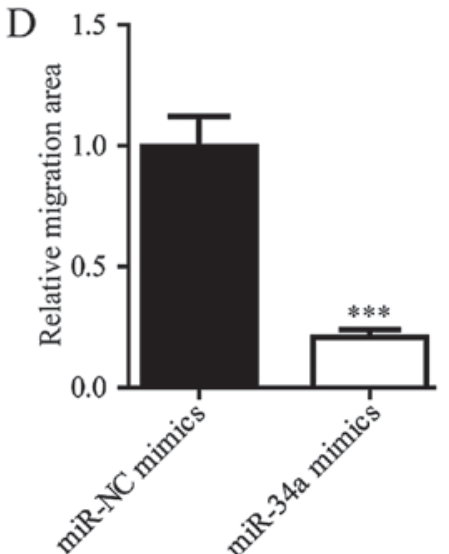



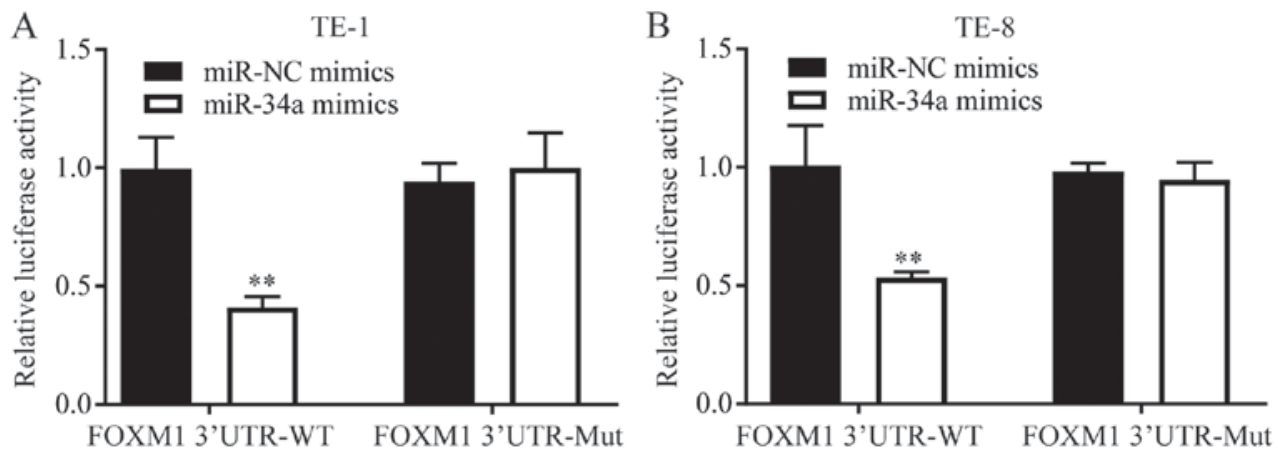

Figure 4. miR-34a directly repressed FOXM1 expression in ESCC. In (A) TE-1 and (B) TE-8 cells, overexpression of miR-34a decreased the luciferase activity of cells transfected with FOXM1 3'UTR-WT not 3'UTR-Mut. ${ }^{* *} \mathrm{P}<0.01$. FOXM1, forkhead box M1; ESCC, esophageal squamous cell carcinoma.
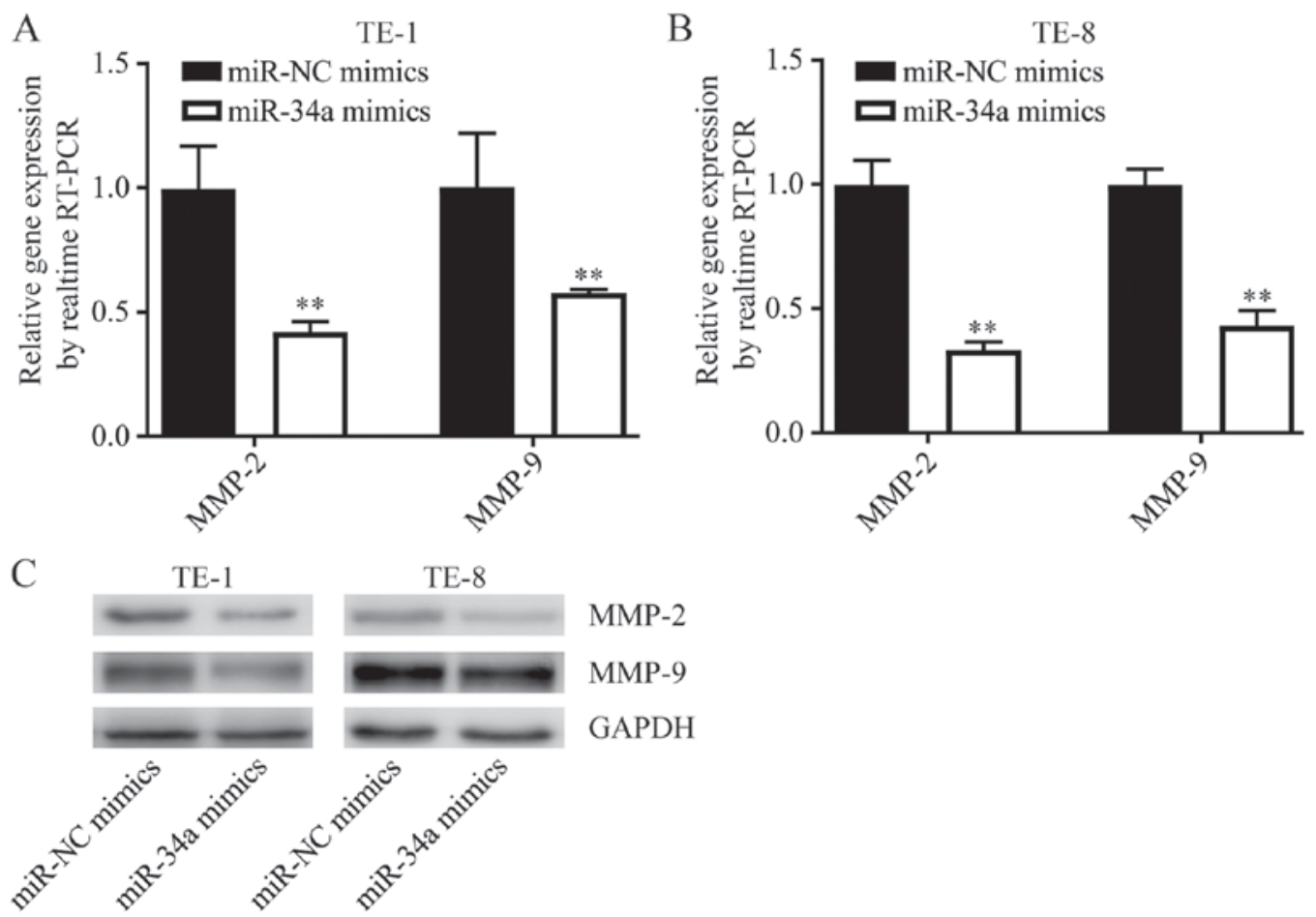

Figure 5. miR-34a suppressed FOXM1 target gene expression in ESCC cells. Overexpression of miR-34a downregulated MMP-2 and MMP-9 mRNA expression, two target genes of FOXM1 which were involved in cell migration regulation, in both (A) TE-1 and (B) TE- 8 cells. (C) This was confirmed via western blotting whereby MMP-2 and MMP-9 protein expression levels were downregulated. ${ }^{* *} \mathrm{P}<0.01$. FOXM1, forkhead box M1; ESCC, esophageal squamous cell carcinoma.

in both TE-1 and TE-8 cells (Fig. 5). These data suggested that miR-34a functioned as a tumor suppressor through tight control of FOXM1 and its target gene expression.

\section{Discussion}

EC incidence ranks fifth among cancers worldwide, and EC is the fourth leading cause of cancer-related mortality in China (15). About $70 \%$ of all EC occurs in China and ESCC accounts for more than $90 \%$ of EC cases (16). Despite the development in surgical techniques, chemotherapy, radiation and perioperative management, the five-year survival rate of ESCC is as low as only $10 \%$ (17). Thus, it is essential to develop new therapeutic approaches to improve patient outcomes.

Increasing evidence has shown that alterations in the expression of miRNAs are associated with the development, prognosis and survival rate of EC (18). Studies have reported the lack of expression of miR-34a in ESCC and colon cancer $(19,20)$. Consistent with those reports, we demonstrated the down-regulation of miR-34a in ESCC patients compared with paired cancer-adjacent normal tissues.

Our in vitro experiment showed that miR-34a overexpression inhibited ESCC cell proliferation and migration, indicating the tumor suppressor role of miR-34a in ESCC, which is consistent with previous studies in ESCC (21) and breast cancer (22).

MMP family proteolytic enzymes are essential for the remodeling of the extracellular matrix, whose degradation is a prerequisite for the invasion and metastasis of cancer (23). In the present study, the protein expression levels of MMP2 and MMP9 were decreased after miR-34a mimics treatment compared with NC treatment.

miR-34a acts as an important tumor suppressor in various cancers by targeting and downregulating CDK4/6, 
cyclin D1, E2F3, MYCN, SIRT1 and Bc12 (11). FOXM1, a transcription factor of the forkhead box family, is involved in the regulation of cell proliferation (24). Aberrant FOXM1 plays an important role in angiogenesis, cell cycle acceleration and metastasis (25-27). FOXM1 promoted cancer progression via elevating the expression of MMP-2 and MMP-9 (14). Furthermore, FOXM1 is overexpressed in many human solid cancers, including breast cancer and colon cancer $(28,29)$.

Although the effects of miR-34a $(30,31)$ as well as FOXM1 $(32,33)$ have already been investigated in ESCC, and miR-34a could regulate the progression of hepatocellular carcinoma via targeting FOXM1 (13), it has not been investigated whether miR-34a could regulate the progression of ESCC via targeting FOXM1. Consistent with these studies, we demonstrated the upregulation of FOXM1 in ESCC patients compared with paired cancer-adjacent normal tissues. Importantly, the FOXM1 level was negatively correlated with the miR-34a level. We also found that miR-34a interacted with a putative binding site in the FOXM1 3'UTR and downregulated the expression of FOXM1.

There are further molecular mechanisms that could be involved, for instance, we only interpret the down regulation of MMP2 and MMP9 as a consequence of the miR-34a-mediated down regulation of FOXM1, which will be further explored to show that the observed effect is actually mediated by FOXM1.

These results suggest that miR-34a is possibly a therapeutic target for ESCC.

\section{Acknowledgements}

Not applicable.

\section{Funding}

The present study was supported with Funding of Hubei Province, China (grant no: WJ2015MB22).

\section{Availability of data and materials}

The datasets used and/or analyzed during the present study are available from the corresponding author on reasonable request.

\section{Authors' contributions}

YX was involved in the study conception and design. HZ, LY, $\mathrm{XX}, \mathrm{ML}, \mathrm{RG}, \mathrm{DL}, \mathrm{QH}$ and YL were involved in acquisition of data. HZ, GD and YX were involved in the analysis and interpretation of data. $\mathrm{HZ}$ and $\mathrm{YX}$ prepared and revised the manuscript.

\section{Ethics approval and consent to participate}

The present study was performed under the supervision of the Ethics Committee of Chibi Pu Spinning Hospital. Written consents were provided by all patients.

\section{Patient consent for publication}

All patients consented the publication of data in this study.

\section{Competing interests}

The authors declare that they have no competing interests.

\section{References}

1. Hongo M, Nagasaki Y and Shoji T: Epidemiology of esophageal cancer: Orient to occident. Effects of chronology, geography and ethnicity. J Gastroenterol Hepatol 24: 729-735, 2009.

2. Zhou SL and Wang LD: Circulating microRNAs: Novel biomarkers for esophageal cancer. World J Gastroenterol 16: 2348-2354, 2010

3. David S and Meltzer SJ: MicroRNA involvement in esophageal carcinogenesis. Curr Opin Pharmacol 11: 612-616, 2011.

4. Brown LM, Hoover R, Silverman D, Baris D, Hayes R, Swanson GM, Schoenberg J, Greenberg R, Liff J, Schwartz A, et al: Excess incidence of squamous cell esophageal cancer among US Black men: Role of social class and other risk factors. Am J Epidemiol 153: 114-122, 2001.

5. Zhang C, Wang C, Chen X, Yang C, Li K, Wang J, Dai J, Hu Z, Zhou X, Chen L, et al: Expression profile of microRNAs in serum: A fingerprint for esophageal squamous cell carcinoma. Clin Chem. 56: 1871-1879, 2010.

6. Jankowski JA and Odze RD: Biomarkers in gastroenterology: Between hope and hype comes histopathology. Am J Gastroenterol 104: 1093-1096, 2009.

7. Patnaik SK, Mallick R and Yendamuri S: MicroRNAs and esophageal cancer. J Gastrointestinal Oncol 1: 55-63, 2010.

8. Bartel DP: MicroRNAs: Genomics, biogenesis, mechanism, and function. Cell 116: 281-297, 2004.

9. Huang J, Zhang SY, Gao YM, Liu YF, Liu YB, Zhao ZG and Yang K: MicroRNAs as oncogenes or tumour suppressors in oesophageal cancer: Potential biomarkers and therapeutic targets. Cell Prolif 47: 277-286, 2014.

10. Garzon R, Marcucci G and Croce CM: Targeting microRNAs in cancer: Rationale, strategies and challenges. Nat Rev Drug Discov 9: 775-789, 2010.

11. Wei JS, Song YK, Durinck S, Chen QR, Cheuk AT, Tsang P, Zhang Q, Thiele CJ, Slack A, Shohet J and Khan J: The MYCN oncogene is a direct target of miR-34a. Oncogene 27: 5204-5213, 2008.

12. Livak KJ and Schmittgen TD: Analysis of relative gene expression data using real-time quantitative PCR and the 2(-Delta Delta C(T)) method. Methods 25: 402-408, 2001.

13. Xu X, Chen W, Miao R, Zhou Y, Wang Z, Zhang L, Wan Y, Dong Y, Qu K and Liu C: miR-34a induces cellular senescence via modulation of telomerase activity in human hepatocellular carcinoma by targeting FoxM1/c-Myc pathway. Oncotarget 6: 3988-4004, 2015.

14. Chen H, Zou Y, Yang H, Wang J and Pan H: Downregulation of FoxM1 inhibits proliferation, invasion and angiogenesis of HeLa cells in vitro and in vivo. Int J Oncol 45: 2355-2364, 2014.

15. Parkin DM, Bray F, Ferlay J and Pisani P: Global cancer statistics, 2002. CA Cancer J Clin 55: 74-108, 2005.

16. Enzinger PC and Mayer RJ: Esophageal cancer. N Engl J Med 349: 2241-2252, 2003.

17. Rice TW, Rusch VW, Apperson-Hansen C, Allen MS, Chen LQ, Hunter JG, Kesler KA, Law S, Lerut TE, Reed CE, et al: Worldwide esophageal cancer collaboration. Dis Esophagus 22: $1-8,2009$

18. Ogawa R, Ishiguro H, Kuwabara Y, Kimura M, Mitsui A, Katada T, Harata K, Tanaka T and Fujii Y: Expression profiling of micro-RNAs in human esophageal squamous cell carcinoma using RTPCR. Med Mol Morphol 42: 102-109, 2009.

19. Lin X, Xu XY, Chen QS and Huang C: Clinical significance of microRNA-34a in esophageal squamous cell carcinoma. Genet Mol Res 14: 17684-17691, 2015.

20. Tazawa H, Tsuchiya N, Izumiya $M$ and Nakagama $H$ : Tumor-suppressive miR-34a induces senescence-like growth arrest through modulation of the E2F pathway in human colon cancer cells. Proc Natl Acad Sci USA 104: 15472-15477, 2007.

21. Shi H, Zhou S, Liu J, Zhu J, Xue J, Gu L and Chen Y: miR-34a inhibits the in vitro cell proliferation and migration in human esophageal cancer. Pathol Res Pract 212: 444-449, 2016.

22. Xiao X, Huang X, Ye F, Chen B, Song C, Wen J, Zhang Z, Zheng G, Tang H and Xie X: The miR-34a-LDHA axis regulates glucose metabolism and tumor growth in breast cancer. Sci Rep 6: 21735, 2016. 
23. Cathcart J, Pulkoski-Gross A and Cao J: Targeting matrix metalloproteinases in cancer: Bringing new life to old ideas. Genes Dis 2: 26-34, 2015.

24. Ye H, Kelly TF, Samadani U, Lim L, Rubio S, Overdier DG, Roebuck KA and Costa RH: Hepatocyte nuclear factor 3/fork head homolog 11 is expressed in proliferating epithelial and mesenchymal cells of embryonic and adult tissues. Mol Cell Biol 17: 1626-1641, 1997

25. Li Q, Zhang N, Jia Z, Le X, Dai B, Wei D, Huang S, Tan D and $\mathrm{Xie} \mathrm{K}$ : Critical role and regulation of transcription factor FoxM1 in human gastric cancer angiogenesis and progression. Cancer Res 69: 3501-3509, 2009.

26. Monteiro LJ, Khongkow P, Kongsema M, Morris JR, Man C, Weekes D, Koo CY, Gomes AR, Pinto PH, Varghese V, et al: The Forkhead Box M1 protein regulates BRIP1 expression and DNA damage repair in epirubicin treatment. Oncogene 32: 4634-4645, 2013.

27. Schimmel J, Eifler K, Sigurðsson JO, Cuijpers SA, Hendriks IA, Verlaan-de Vries M, Kelstrup CD, Francavilla C, Medema RH, Olsen JV and Vertegaal AC: Uncovering SUMOylation dynamics during cell-cycle progression reveals FoxM1 as a key mitotic SUMO target protein. Mol Cell 53: 1053-1066, 2014.
28. Madureira PA, Varshochi R, Constantinidou D, Francis RE, Coombes RC, Yao KM and Lam EW: The Forkhead box M1 protein regulates the transcription of the estrogen receptor alpha in breast cancer cells. J Biol Chem 281: 25167-25176, 2006.

29. Li D, Peng Z, Tang H, Wei P, Kong X, Yan D, Huang F, Li Q, Le X, Li Q and Xie K: KLF4-mediated negative regulation of IFITM3 expression plays a critical role in colon cancer pathogenesis. Clin Cancer Res 17: 3558-3568, 2011.

30. Zuo J, Zhu K, Wang Y and Yu Z: MicroRNA-34a suppresses invasion and metastatic in esophageal squamous cell carcinoma by regulating CD44. Mol Cell Biochem 443: 139-149, 2017.

31. Nie J, Ge X, Geng Y, Cao H, Zhu W, Jiao Y, Wu J, Zhou J and Cao J: miR-34a inhibits the migration and invasion of esophageal squamous cell carcinoma by targeting Yin Yang-1. Oncol Rep 34: 311-317, 2015

32. Song L, Wang X and Feng Z: Overexpression of FOXM1 as a target for malignant progression of esophageal squamous cell carcinoma. Oncol Lett 15: 5910-5914, 2018

33. Hui MK, Chan KW, Luk JM, Lee NP, Chung Y, Cheung LC, Srivastava G, Tsao SW, Tang JC and Law S: Cytoplasmic Forkhead box M1 (FoxM1) in esophageal squamous cell carcinoma significantly correlates with pathological disease stage. World J Surg 36: 90-97, 2012. 